\title{
SYNTHESIS OF SIGN DETERIORATION RATES ACROSS THE UNITED STATES
}

Venkata Pavan K. Immaneni

Graduate Research Assistant

Department of Civil, Construction, and Environmental Engineering

North Carolina State University

Raleigh, NC 27695-7908

Telephone 646-623-7424

Email ivpavan@yahoo.com

Joseph E. Hummer, Ph.D., P.E., Professor

Department of Civil, Construction, and Environmental Engineering

North Carolina State University

Raleigh, NC 27695-7908

Telephone 919-515-7733, Fax 919-515-7908

Email hummer@eos.ncsu.edu

William J. Rasdorf, Ph.D., P.E., Professor

Department of Civil, Construction, and Environmental Engineering

North Carolina State University

Raleigh, NC 27695-7908

Telephone 919-515-7637, Fax 919-515-7908

Email rasdorf@eos.ncsu.edu

Elizabeth A. Harris

Graduate Research Assistant

Department of Civil, Construction, and Environmental Engineering

North Carolina State University

Raleigh, NC 27695-7908

Telephone 919-836-1989

Email liz harris@ncsu.edu

Chunho Yeom

Graduate Research Assistant

Department of Civil, Construction, and Environmental Engineering

North Carolina State University

Raleigh, NC 27695-7908

Telephone 919-607-4389

Email cyeom@ncsu.edu

Word Count: 7759 Words + 15 Figures and Tables 


\title{
SYNTHESIS OF SIGN DETERIORATION RATES ACROSS THE UNITED STATES
}

\author{
By
}

\begin{abstract}
Venkata Pavan K. Immaneni, Joseph E. Hummer, Ph.D., P.E., William J. Rasdorf, Ph.D., P.E., Elizabeth A. Harris, and Chunho Yeom
\end{abstract}

\begin{abstract}
In response to minimum retroreflectivity standards, transportation departments are implementing sign asset management strategies, which rely upon knowledge of how retroreflectivity decreases as signs weather and age. To provide this knowledge, the authors field-measured over 1000 inservice signs in scattered North Carolina Department of Transportation (NCDOT) divisions, collecting age and retroreflectivity data for white, yellow, red, and green signs and for ASTM sheeting Types I and III. Data from this study and data from five similar US efforts were analyzed using regression to identify the best available deterioration rate estimates, finding that retroreflectivity minimums are usually reached 8 to 15 years after installation.

Initial results indicated that the best-fitting relationships between retroreflectivity and age were generally linear and that these models were significant despite having low $\mathrm{R}^{2}$ values. Because age did not explain some of the variance, the authors re-evaluated their data including NCDOT divisions as a factor, finding that sign deterioration differed significantly by division, indicating that handling practices, manufacturing differences, and environmental exposure may be key deterioration model factors that merit future study.
\end{abstract}

Keywords: sign, retroreflectivity, deterioration, sign age, sign deterioration, unfunded mandate, sign management, asset management

INTRODUCTION

SIGN RETROREFLECTIVITY STUDIES

Data Collection Procedures

Deterioration Curves and Models

GENERATING NEW CURVES

SYNTHESIS OF STUDIES

DETERIORATION MODEL INCORPORATING SIGN LOCATION

Survival Analysis

Analysis Modifications

Significance of Sign Location

Average Sign Lifetime Estimates for the Division Separated Regression Models

SUMMARY AND CONLCUSIONS

FUTURE RESEARCH

* Outline is provided only for reviewers' convenience 


\title{
SYNTHESIS OF SIGN DETERIORATION RATES ACROSS THE UNITED STATES
}

\author{
By
}

\author{
Venkata Pavan K. Immaneni, Joseph E. Hummer, Ph.D., P.E., William J. Rasdorf, Ph.D., P.E., \\ Elizabeth A. Harris, and Chunho Yeom
}

\section{INTRODUCTION}

It is important that state departments of transportation (DOTs) have effective sign testing and replacement programs to significantly reduce safety risks to motorists. Sign performance during nighttime driving is dependent on retroreflectivity, measured by a coefficient of retroreflection. The coefficient of retroreflection $\left(\mathrm{R}_{\mathrm{a}}\right)$ is the ratio of light that a sign reflects to a driver (candela, cd) to the light that illuminates the sign (lux, lx), per unit area (square meter, $\mathrm{m}^{2}$ ). Sign replacement procedures should be based in large part on the deterioration of a sign's retroreflectivity over time.

Beginning in 1984, the Center for Auto Safety petitioned the Federal Highway Administration (FHWA) to establish standards for retroreflectivity. In 1993, the Department of Transportation Appropriation Act stated that the US Secretary of Transportation should revise the Manual for Uniform Traffic Control Devices (MUTCD) to include "a standard for a minimum level of retroreflectivity that must be maintained for pavement markings and signs, which shall apply to all roads open to public travel" (AASHTO 2000). FHWA produced two related reports in 1998. One report aimed at "evaluating the applicability and practicality of the minimum-maintained levels of sign retroreflectivity proposed by FHWA and the hand-held retroreflectometer that measures sign retroreflectivity" (McGee and Paniati 1998). The other report aimed at providing explanations and procedures to assist agencies in developing their own sign management systems to meet the minimum retroreflectivity requirements (McGee and Taori 1998).

Although the 2000 edition of the MUTCD did not include retroreflectivity guidelines, Section 2A.09 of the MUTCD was reserved for their future addition. Revised standards were proposed by an FHWA contractor in 2003 (Carlson and Hawkins 2003) and included in Revision 2 of the 2003 edition of the MUTCD effective January 2008 (FHWA 2007). Now that these new standards have been adopted, both compliance (for the safety and well-being of the public) and proof of compliance (to protect against lawsuits) are necessary.

The new retroreflectivity requirements present several issues to agencies responsible for sign replacement and maintenance. In the case of North Carolina (NC), the NCDOT owns and maintains approximately 78,000 miles of roadway. Interstate and other primary roads contain approximately 388,000 signs and secondary roads contain approximately 605,000 signs (Kirtley and Rasdorf 2001; Palmquist and Rasdorf 2002). Each of these signs may need to be easily identified and located as part of a sign management system. To determine if a sign needs replacement, there needs to be some method of observing and/or measuring retroreflectivity or of forecasting when signs will fail the minimum standard. Other state DOTs face similar challenges. 
To meet the new minimum standard, state DOTs may have to develop or improve their own sign inspection and replacement procedures. There are currently two primary methods for assessing the retroreflectivity of a sign in the field. The first is a visual assessment wherein sign condition is evaluated based on the observers' visual observation without using any retroreflectivity measurement equipment. Visual inspection is performed at night using vehicle headlights for illumination. The second method to assess retroreflectivity utilizes hand-held retroreflectometers to quantitatively measure each sign. Neither of the two methods is completely satisfying. On one hand the accuracy of visual assessment is questionable because different inspectors may have varying visual observations of the same sign, even given the same set of inspection guidelines. On the other hand the use of hand-held retroreflectometers is labor intensive and time-consuming, requiring a technician to exit from their vehicle, walk up to the sign, hold up the instrument, and take multiple readings per color.

The purpose of this paper is to report on our achievements in conducting a comprehensive study of retroreflectivity values including a study and analysis of all publicly available data as well as an independent data collection and analyzing effort. NCSU researchers field-measured the retroreflectivity of over 1000 in-service signs. Data from this study and the findings from five other similar efforts across the US in recent years were analyzed to identify the best estimates of the deterioration rate. To the extent that other DOTs have signing and sign inspection practices like those in $\mathrm{NC}$, these data may also help them in making decisions about inspection and replacement practices.

\section{SIGN RETROREFLECTIVITY STUDIES}

The new minimum standard for retroreflectivity has been referred to by some as the nation's largest unfunded mandate. The standard deals with one of the most safety-critical elements of our highway system. It is imperative now that quality data be available in which to base strategic decisions for meeting the standard. Yet there have been only a limited number of such studies. A careful analysis of the data from these studies and a critical analysis of them is provided in this paper. No such comprehensive analysis has previously been attempted. In addition, data from a new NCSU study is included.

A total of six sign retroreflectivity studies and tests were examined in the process of collecting sign retroreflectivity data for use in a deterioration model. These studies were conducted by the FHWA (Black et al. 1991), the State of Oregon (Kirk et. al. 2001), Louisiana State University, (Wolshon et al. 2002), Purdue University (Bischoff and Bullock 2002), and NCSU (Rasdorf et al. 2006). In addition, the American Association of State Highway and Transportation Officials' (AASHTO) tests are discussed although they only test signs for three years (AASHTO 2005a).

\section{Data Collection Procedures}

This section describes the data collection procedures used in the six studies under consideration. Table 1 summarizes the details of each study. Each of the six studies used either the 920 SEL or RetroSign ${ }^{\circledR} 4500$ retroreflectometer to measure sign retroreflectivity. The FHWA, Oregon, Louisiana, and Purdue studies took measurements of signs after they had been cleaned. The Oregon study used data only from cleaned signs while the others used a combination of both. Study sample sizes ranged from 137 signs in the Oregon study to 6000 signs in the FHWA study. 
The FHWA and AASHTO studies were conducted at sites across the US and the Purdue study measured signs in Indiana.

Table 1. Summary of Sign Retroreflectivity Studies

\begin{tabular}{|c|c|c|c|c|c|c|}
\hline Year & Organization & $\begin{array}{l}\text { Retroreflectometer } \\
\text { Model Used }\end{array}$ & $\begin{array}{c}\text { Sign Type } \\
\text { Studied }\end{array}$ & $\begin{array}{c}\text { Sheeting } \\
\text { Color } \\
\text { Studied } \\
\end{array}$ & $\begin{array}{c}\text { Sign } \\
\text { Cleaning }\end{array}$ & $\begin{array}{c}\text { Sample } \\
\text { Size }\end{array}$ \\
\hline 1991 & FHWA & $920 \mathrm{SEL}$ & I, III & $\begin{array}{l}\text { White, } \\
\text { Yellow, } \\
\text { Green, and } \\
\text { Red }\end{array}$ & $\begin{array}{c}\text { Uncleaned } \\
\text { and Cleaned } \\
\text { Data }\end{array}$ & 6,000 \\
\hline On-going & AASHTO & RetroSign $® 4500$ & $\begin{array}{l}\text { All Sign } \\
\text { Types }\end{array}$ & $\begin{array}{l}\text { All Sign } \\
\text { Colors }\end{array}$ & $\begin{array}{l}\text { Uncleaned } \\
\text { Data }\end{array}$ & growing \\
\hline 2001 & State of Oregon & RetroSign ${ }^{\circledR} 4500$ & III & $\begin{array}{l}\text { White, } \\
\text { Yellow, } \\
\text { Green and } \\
\text { Red }\end{array}$ & Cleaned Data & 137 \\
\hline 2002 & $\begin{array}{c}\text { Louisiana State } \\
\text { University }\end{array}$ & $920 \mathrm{SEL}$ & I, III & $\begin{array}{l}\text { White, } \\
\text { Yellow, and } \\
\text { Green }\end{array}$ & $\begin{array}{c}\text { Uncleaned } \\
\text { and Cleaned } \\
\text { Data }\end{array}$ & 237 \\
\hline 2002 & $\begin{array}{l}\text { Purdue } \\
\text { University }\end{array}$ & $920 \mathrm{SEL}$ & III & $\begin{array}{l}\text { White, } \\
\text { Yellow, and } \\
\text { Red }\end{array}$ & $\begin{array}{c}\text { Uncleaned } \\
\text { and Cleaned } \\
\text { Data }\end{array}$ & 1,341 \\
\hline 2006 & $\begin{array}{l}\text { North Carolina } \\
\text { State University }\end{array}$ & RetroSign ${ }^{\circledR} 4500$ & I, III & $\begin{array}{l}\text { White, } \\
\text { Yellow, } \\
\text { Green, and } \\
\text { Red }\end{array}$ & $\begin{array}{l}\text { Uncleaned } \\
\text { Data }\end{array}$ & 1,057 \\
\hline
\end{tabular}

\section{Deterioration Curves and Models}

Each study described above collected a variety of data to learn about the various factors affecting sign performance. This section presents the development of deterioration models for each of the previously discussed studies.

\section{FHWA}

The FHWA found sign age to be a dominant predictor of sign deterioration. Factors such as precipitation, degree days, and elevation had only a slight effect on the deterioration of some of the sign colors and sheeting types. Each of their regression equations was found to be significant, but had a low explained variance ( $R^{2}$ value) (Black et al. 1991). The $R^{2}$ values provide an indication of the extent to which the regression model curve approximated the actual data. In other words, the $\mathrm{R}^{2}$ is a descriptive measure on a scale from 0 to 1 of the proportion of variation in the retroreflectivity data that is explained by sign age, with a value of 1 indicating all variation in retroreflectivity can be predicted from sign age. The original researchers (Black et al.) performed linear regression for white, yellow, red, and green sheeting colors and sheeting 
Types II and III-A. Their findings indicate a consistent reduction of retroreflectivity as age increases. However, there was an exception. The plot of red Type III-A showed increasing retroreflectivity as a sign aged. The reason given for this was that red ink was screened onto white retroreflective sheeting. This red ink fades over time exposing the more reflective sheeting behind it, causing the retroreflectivity to increase.

\section{$\underline{\mathrm{AASHTO}}$}

AASHTO's National Transportation Product Evaluation Program (NTPEP) collects data for only the first three years of sign life because their testing program objective is to evaluate the initial and short-term performance of transportation products. Signs are weathered facing southward and angled $45^{\circ}$ from the horizontal (AASHTO 2005b). AASHTO believes that this doubles the sign deterioration rate, such that three years in an AASHTO test deck is equivalent to six years in the field (Carlson and Hawkins 2003). A plot of retroreflectivity versus age for the NTPEP 2002-2005 data for $3 \mathrm{M}^{\mathrm{TM}}$ High Intensity (Type III) white sheeting is shown in Figure 1 for the Flagstaff, Arizona (AZ) and Wilmington, NC testing locations (AASHTO 2006).

Each data point in Figure 1 represents the mean of three samples at each testing location, and the test results represent six years of effective field deterioration. The minimum retroreflectivity standard for Type III white sheeting is $50 \mathrm{~cd} / \mathrm{lx} / \mathrm{m}^{2}$ (Carlson and Hawkins 2003). The age coefficients for the linear regression with retroreflectivity as the dependent variable have low $\mathrm{p}$ values of 0.010 for $\mathrm{AZ}$ and 0.025 for NC. Therefore, the AASHTO data indicate that there is a significant deterioration of white Type III signs over an effective six-year period. The average decline in retroreflectivity for the two testing locations was approximately $25 \mathrm{~cd} / \mathrm{lx} / \mathrm{m}^{2}$. Note that there is some increase in retroreflectivity from the installation date to the $6^{\text {th }}$ month in the AZ data and from the $24^{\text {th }}$ month to the $36^{\text {th }}$ month $\left(48^{\text {th }}\right.$ to $\left.72^{\text {nd }}\right)$ in the NC data. These small increases, which are on the magnitude of $1 \mathrm{~cd} / \mathrm{l} \mathrm{x} / \mathrm{m}^{2}$, are due to a combination of the variability of readings across the sign face and retroreflectometer measurement error.

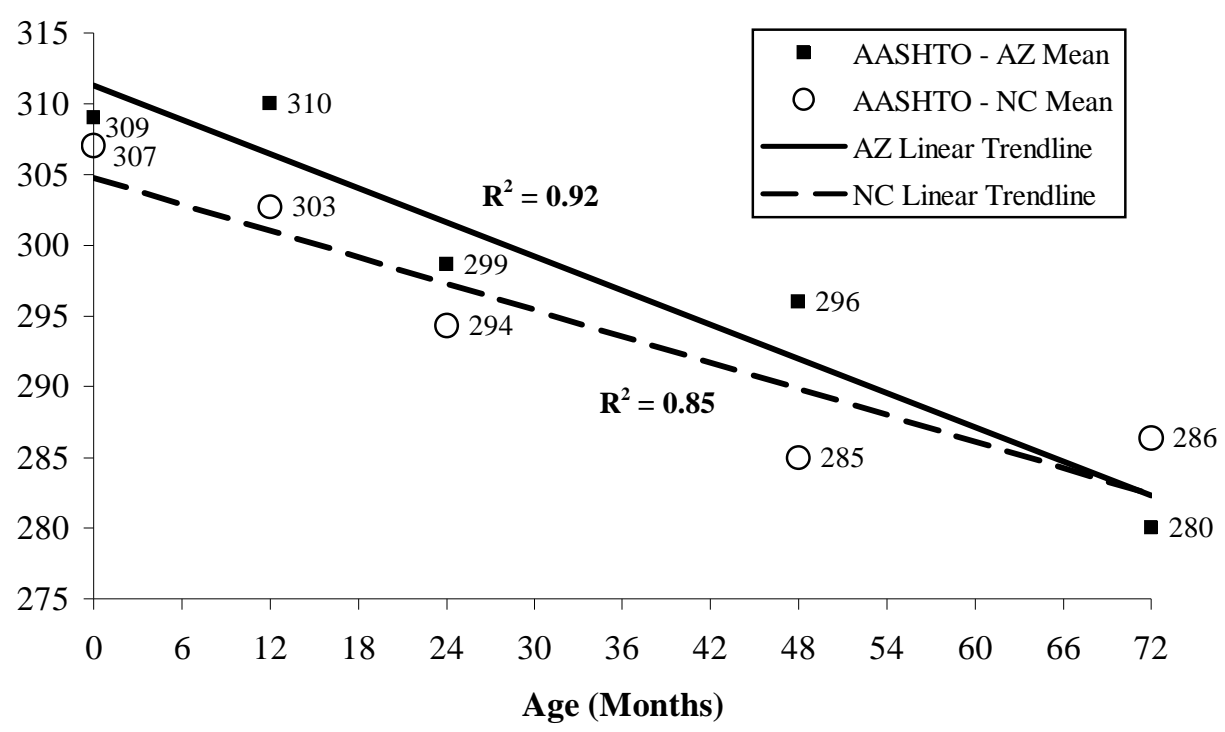

Figure 1. AASHTO $\mathbf{R}_{\mathrm{a}}$ Deterioration for $3 \mathrm{M}^{\mathrm{TM}}$ High Intensity (Type III) White Signs 


\section{Oregon}

To determine the relationship between sign age and retroreflectivity, OR researchers plotted the average sign retroreflectivity (SIA) value against its installation year. Figure 2 shows the plots for each sign color (data are for washed signs). The trend lines showed weak relationships between sign age and retroreflectivity values, which is evident from the $\mathrm{R}^{2}$ values of 0.033 , $0.094,0.008$ and 0.103 for white, yellow, green, and red, respectively.

The OR researchers cited two factors to explain the apparent weak relationships. First, the sign age range may not have been broad enough to provide a complete picture of sign performance over time. Second, the installation year data may not have been entirely reliable. They suggested that a more carefully controlled investigation covering a larger time span would be needed to further explore whether any stronger relationship exists between sign retroreflectivity and sign age.

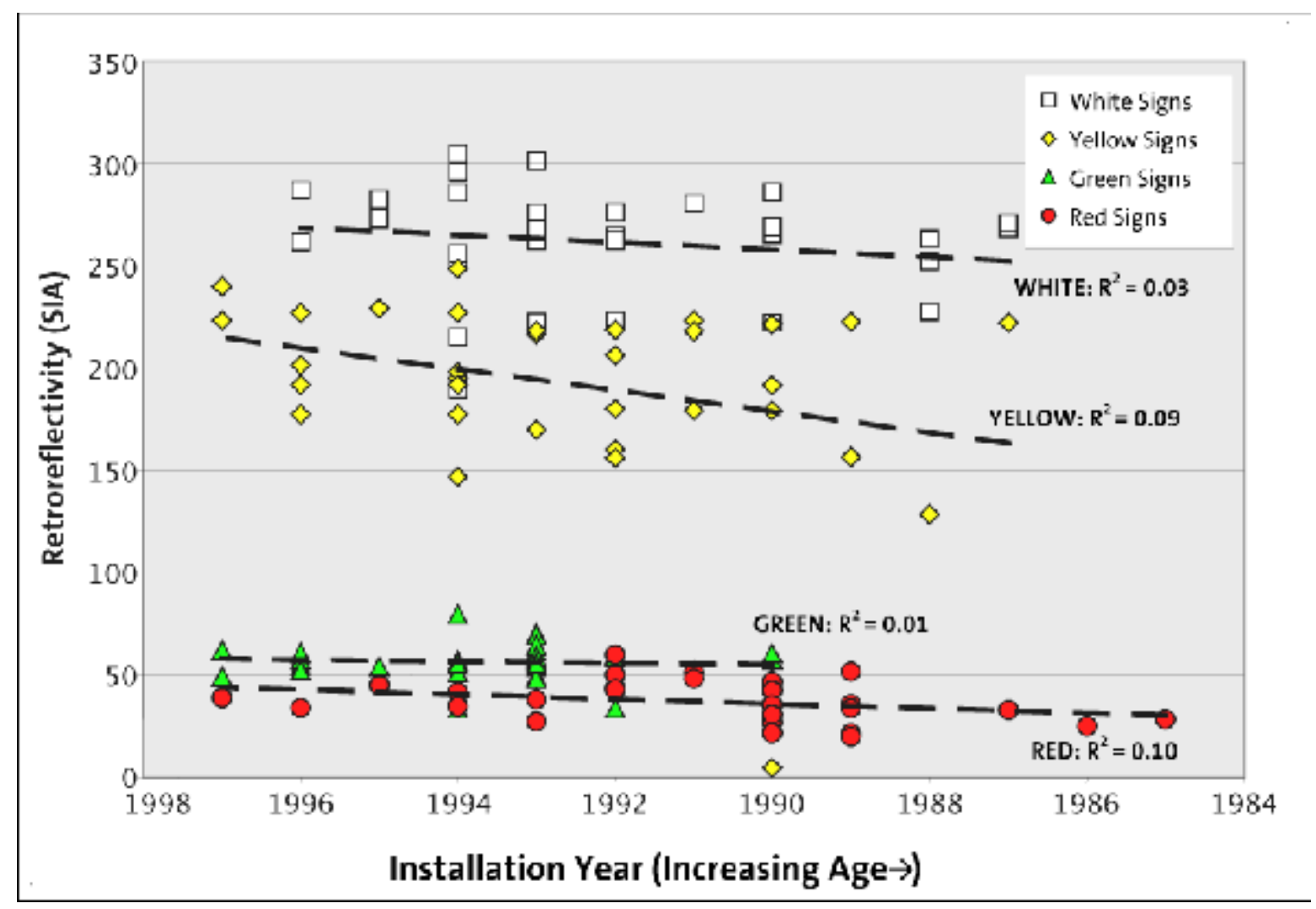

Figure 2. Oregon Linear $\mathbf{R}_{\mathrm{a}}$ vs. Age Deterioration Curves

\section{Louisiana}

Information gained from early performance and sign cleaning evaluations in Louisiana indicated that differences between several of the sheeting type and color categories existed. To further evaluate these results, additional analyses were conducted to determine which factors (if any) contributed to sign deterioration over time. This process was made somewhat more complicated by the potential for interaction between the various factors. 
A set of models to estimate sign performance based on specific properties and environmental characteristics was developed using linear modeling procedures. Both orientation and offset distance factors were included despite an initial finding that neither had a statistically significant effect on sign degradation over time. These two parameters were included because their effects were not shown to be non-existent. Separate equations were developed for each color and sheeting type sign group, consistent with the specification criteria for each. Separate equations were also developed for the wiped and unwiped data sets.

The deterioration equations developed in the study were all linear. They revealed the following interesting trends:

- Type I signs of all colors seem to have deteriorated with age but performed satisfactorily both before and somewhat after the sign manufacturer's warranty period.

- Type III white and green signs showed superior performance as their trend lines stayed flat. However, yellow Type III sheeting seems to have deteriorated more significantly with age, as shown in Figure 3.

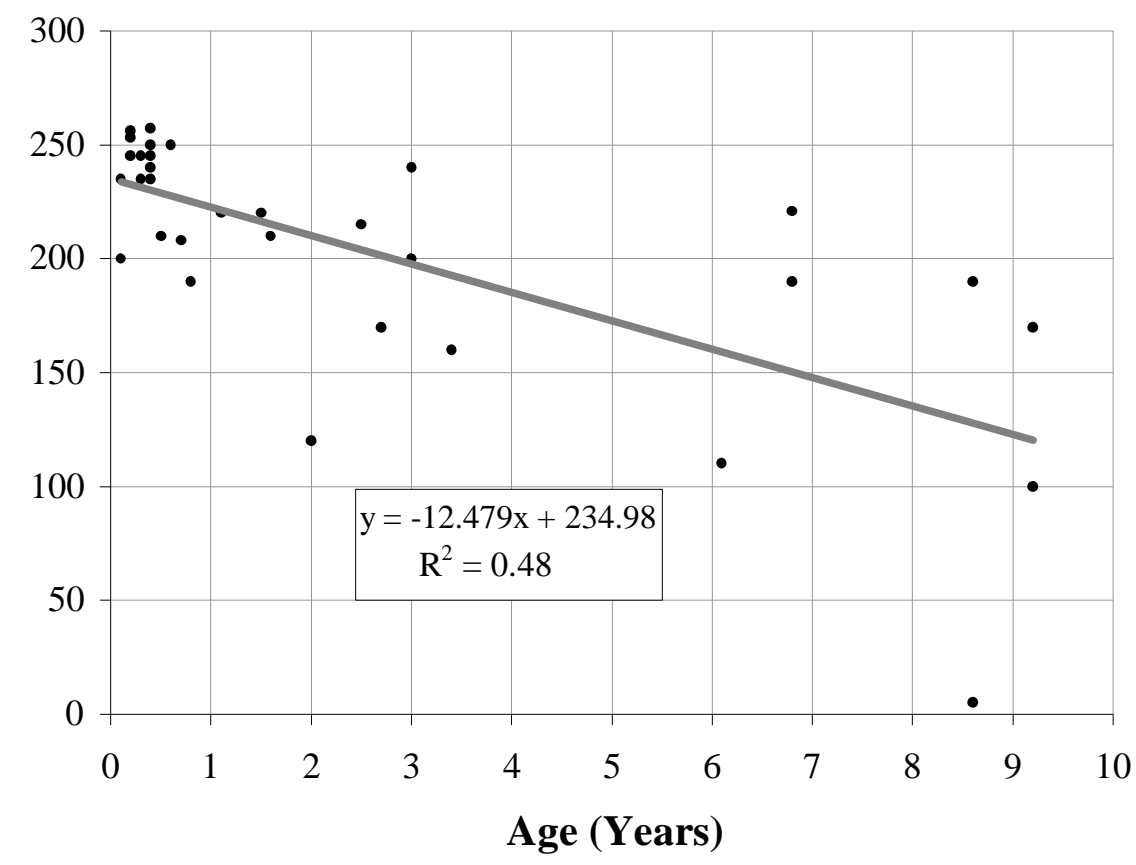

\section{Figure 3. Louisiana Linear $\mathbf{R}_{\mathrm{a}}$ Deterioration Curves for Type III Yellow Signs}

\section{$\underline{\text { Purdue }}$}

Purdue researchers plotted linear curves of retroreflectivity versus age for three colors (red, yellow, and white) (Bischoff and Bullock 2002). They concluded that red is the sheeting most affected by weathering due to the nature of the red color itself. Purdue researchers developed a plot of average retroreflectivity versus age for Type III red signs. In doing so they found that the 
$\mathrm{R}^{2}$ value for the least-squares linear trend line was 0.32 , which indicates some unexplained variance in the model.

They also plotted retroreflectivity of white Type III signs with age, as shown in Figure 4. The majority of samples collected fell between 0 and 10 years of age but the findings indicate that there were more signs older than 10 years compared to the red sample. Almost all of the white Type III signs were well above the proposed minimum standards and the least-squares linear regression model line was basically flat, meaning that there really is no apparent downward trend in retroreflectivity with age as was also the case for the red samples. However, the $\mathrm{R}^{2}$ value of 0.01 for the least-squares line indicates the model's high level of unexplained variance.

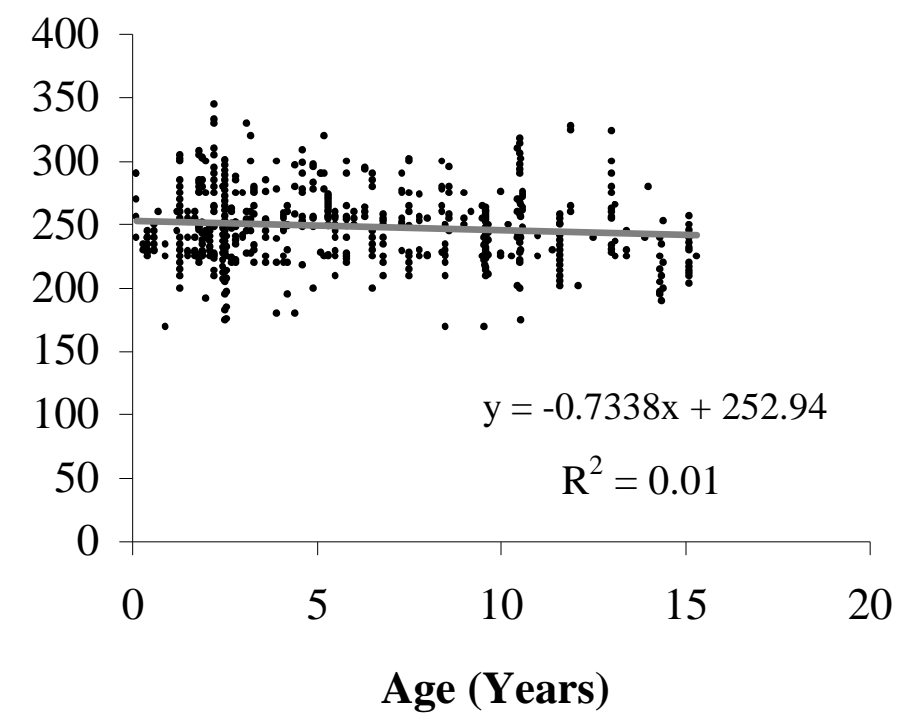

\section{Figure 4. Purdue Linear $\mathbf{R}_{\mathrm{A}}$ Deterioration Curve for Type III White Signs}

A similar analysis was conducted for Type III yellow signs. From the results it was clear that there was an apparent downward trend as age increased. This downward trend was not as steep as for signs with red backgrounds, but was more so than for white background signs. The $\mathrm{R}^{2}$ value of 0.19 means the model explains the variance slightly better than the model for white signs, but the data are still notably scattered.

\section{NCSU}

The NCSU research team collected data on 1,057 white, yellow, red, and green signs on Types I and III sheeting. Figure 5 shows the five common regression types (linear, logarithmic, polynomial, power, and exponential) used to try to establish a least-squares fit with the NCSU data for Type I red signs. The models found a clear deterioration trend with $\mathrm{R}^{2}$ values of over 0.35 in four cases (linear, polynomial, logarithmic, and exponential). Note that the data also showed that about $40 \%$ of the signs in the data set are below the FHWA minimum value of 7 $\mathrm{cd} / \mathrm{lux} / \mathrm{m}^{2}$ for Type I red signs. This is a significant percentage of non-conforming signs. 
Similarly, five regression models were determined for the other seven sign type and color combinations and $\mathrm{R}^{2}$ values were obtained. Based on the $\mathrm{R}^{2}$ values, recommendations for the best fit curves were formulated. The recommendations from the NCSU data are as follows:

- Type I White - None of the curves fit well

- Type I Yellow - Linear, polynomial, and exponential

- Type I Red - Linear, polynomial, and exponential

- Type I Green - Linear and polynomial

- Type III White - None of the curves fit well

- $\quad$ Type III Yellow - Polynomial

- Type III Red - Linear, polynomial, and exponential

- $\quad$ Type III Green - Polynomial

The NCSU data uncovered an interesting observation that results from local practices. NCDOT utilizes a program of visual inspection to maintain its signs. Because statewide training is provided for its inspectors, the NCDOT achieves a degree of uniformity in its sign replacement practices. This is evident in its data. Furthermore, it was found that the age at which a sign reaches the retroreflectivity level where NCDOT inspectors tend to replace signs can be considered to be the end of sign life. For white and yellow signs the NCDOT visual minimum was found to be $20 R_{a}$, and for red and green signs the minimum was $4 R_{a}$ (Rasdorf et al. 2006). While these values are significantly below the new minimums of $50 \mathrm{R}_{\mathrm{a}}$ for white and yellow and $7 \mathrm{R}_{\mathrm{a}}$ for red and green signs, they are uniformly adhered to and can be considered the effective "state" minimums.

\section{GENERATING NEW MODELS}

It was found to be necessary to fit curves to the raw data from both the Purdue and Oregon studies to establish a common comparison basis. While the LA study reported high $\mathrm{R}^{2}$ values (generally over 0.5), the team did not try to fit new curves to data from this study because their data were only for cleaned signs. Thus, the LA data could not be included without improperly biasing the results. The LA study did find a 33\% increase in retroreflectivity readings after cleaning which caused the data scatter to decrease and its correlation to increase. The AASHTO study data were not re-analyzed because only six effective years of data were collected. Finally, the data could not be extracted from the FHWA study (Black et al. 1991) because of the poor quality of the graphs presenting the data in the report. Thus, the FHWA data was also excluded from the effort to fit new models but the research team was able to evaluate the linear regression equations provided in the original report.

Using data from the Purdue (Bischoff and Bullock 2002), Oregon (Kirk et al. 2001), and NCSU (Rasdorf et al. 2006) studies, five different regression types (linear, polynomial, logarithmic, exponential, and power) were performed on the data. When some of the resulting regression models suggested that the retroreflectivity of signs would start increasing after a certain age. Because this is unreasonable, these illogical models were not further considered. Also some of the models became nearly horizontal after some time, implying that (when extrapolated) the signs would last for over 80 years, which is also illogical. 

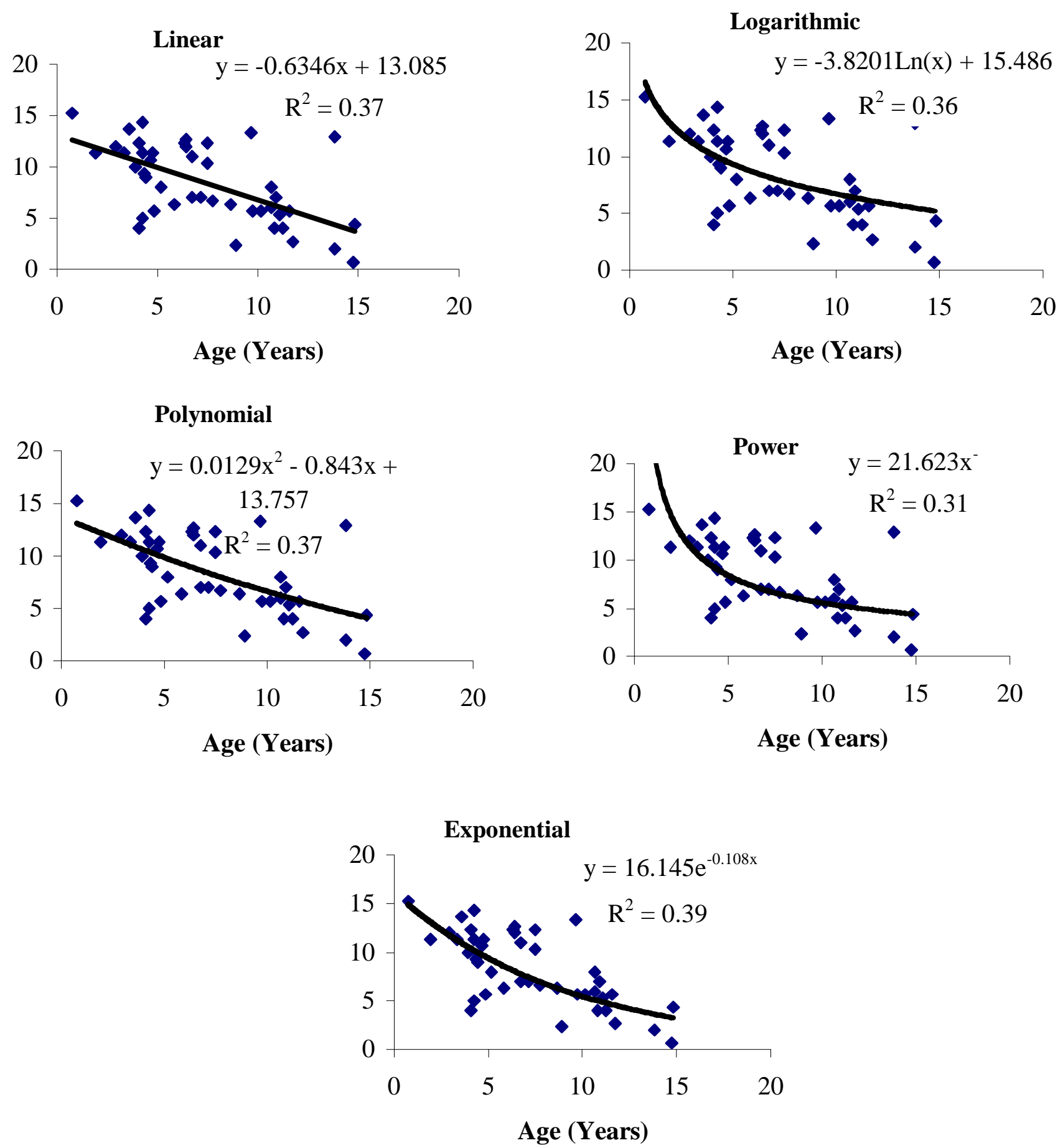

Figure 5. NCSU $R_{A}$ Deterioration Curves for Type I Red Signs 
A few sample plots from this effort are shown in Figure 6 where linear and polynomial models were fitted to the data for red Type III signs from the Purdue study. It is clear from the trend lines that the red Type III sheeting deteriorates with age. The $\mathrm{R}^{2}$ values for these curves are around 0.35 , which is relatively good compared to some other models examined earlier in the paper. In Figure 6 the polynomial trend line shows a steady downward deterioration until 13 years but then the parabolic regression line tends to unrealistically start heading upward. Hence, this polynomial curve is likely a poor choice for any simulation.
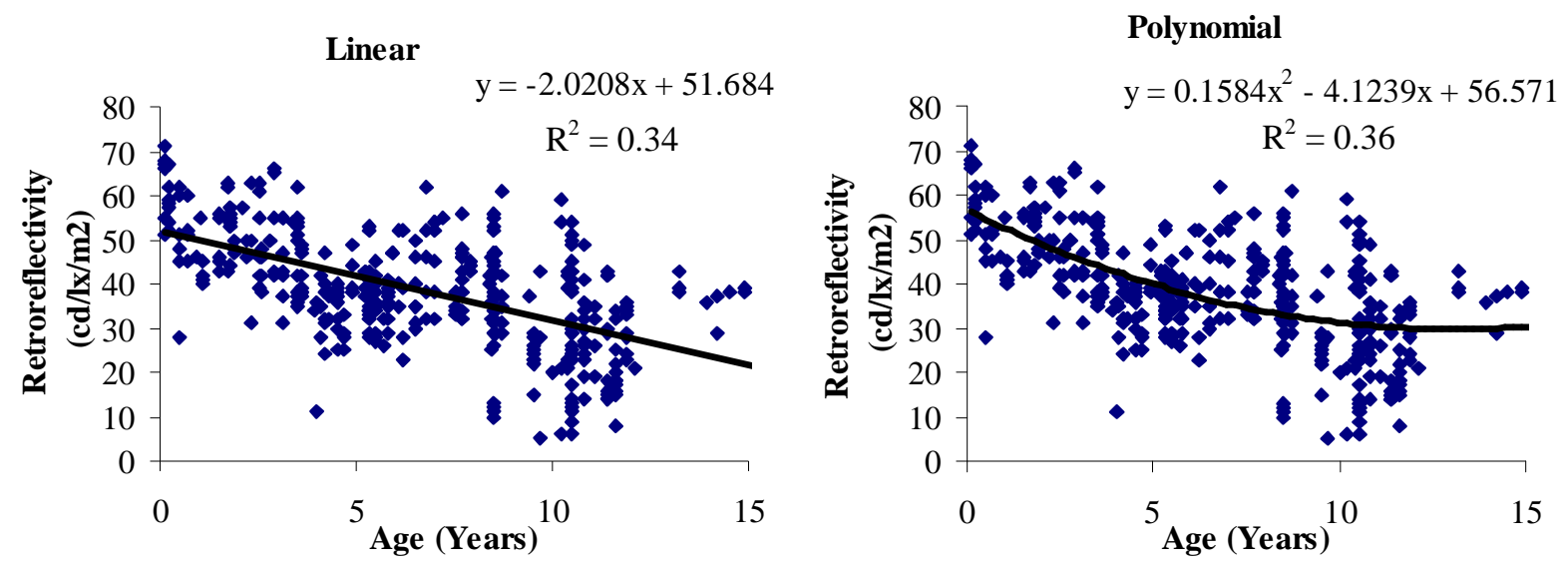

Figure 6. Reanalysis of Purdue $\mathbf{R}_{\mathrm{a}}$ Deterioration Curves for Type III Red Signs

\section{SYNTHESIS OF STUDIES}

The $\mathrm{R}^{2}$ values of the regression models from the original FHWA study analysis, the new NCSU data, the re-analyzed Oregon data, and the re-analyzed Purdue data have been compiled in Tables 2 through 5. These tables also show the sign age when each curve reaches the retroreflectivity level where NCDOT sign inspectors tend to replace signs during their visual inspection process (Rasdorf et. al. 2006). For white and yellow signs the NCDOT visual minimum was $20 \mathrm{R}_{\mathrm{a}}$, and for red and green signs the minimum was $4 \mathrm{R}_{\mathrm{a}}$.

The upward arrow in the Tables 2 to 5 indicate that the slope of the curve began to unrealistically increase at some point. The highlighted cells in the tables identify the curves that were found to be the most reasonable for that particular type of sign and color. For a given sign type and color, if the curve with the highest $\mathrm{R}^{2}$ did not give a satisfactory value for the age at which signs hit the NCDOT visual minimum retroreflectivity, the curve with next best $R^{2}$ value was considered.

Based on Table 2 the following observations emerged. For Type I white signs there was only one feasible option, the FHWA study linear curve model, which was the only study that had a reasonably high $\mathrm{R}^{2}$ value $(0.52)$ and reached $20 \mathrm{R}_{\mathrm{a}}$ at 15 years. It was difficult to decide on a deterioration curve for white Type III signs as the highest $\mathrm{R}^{2}$ value was only 0.19 (FHWA linear curve), and this curve reached the NCDOT visual minimum retroreflectivity at 59 years. It is more likely that these signs would follow a linear pattern for about 20-30 years after which the slope should become steeper and the retroreflectivity would drop to 20 more quickly, but we simply do not have enough data on older signs of this type and color to know this for sure. The $\mathrm{R}^{2}$ values for the other models were too low to be considered. 
Table 2. $\mathbf{R}^{2}$ Values and Extrapolated Sign Life for White Signs

\begin{tabular}{|c|c|c|c|c|c|c|c|c|c|c|}
\hline \multirow{2}{*}{ Stud } & \multicolumn{5}{|c|}{$\mathbf{R}^{2}$ Values } & \multicolumn{5}{|c|}{ Sign Age at $R_{a}=\mathbf{2 0}$} \\
\hline & Lin & Log & Poly & Pow & Exp & Lin & Log & Poly & Pow & Exp \\
\hline \multicolumn{11}{|c|}{ Type I Signs } \\
\hline \multicolumn{2}{|c|}{ FHWA } & - & - & - & - & 15 & - & - & - & - \\
\hline \multicolumn{2}{|c|}{$\mathrm{NCSU}$} & 0.18 & 0.19 & 0.13 & 0.14 & 33 & $>80$ & $\uparrow$ & $>80$ & 37 \\
\hline \multicolumn{11}{|c|}{ Type III Signs } \\
\hline \multicolumn{2}{|c|}{ FHWA } & - & - & 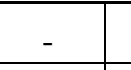 & 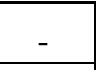 & 59 & - & - & - & - \\
\hline \multicolumn{2}{|c|}{ OR } & 0.01 & 0.01 & 0.01 & 0.00 & $>80$ & $>80$ & $\uparrow$ & $>80$ & $>80$ \\
\hline \multicolumn{2}{|c|}{ Purdue } & 0.00 & 0.03 & 0.00 & 0.01 & $>80$ & $>80$ & 36 & $>80$ & $>80$ \\
\hline \multicolumn{2}{|c|}{$\mathrm{NCSU}$} & 0.01 & 0.01 & 0.01 & 0.01 & $>80$ & $>80$ & $>80$ & $>80$ & $>80$ \\
\hline \multicolumn{11}{|c|}{ Legend } \\
\hline- & \multicolumn{4}{|c|}{$\begin{array}{l}\text { No Data } \\
\end{array}$} & \multicolumn{2}{|c|}{ Poly } & \multicolumn{4}{|c|}{ Polynomial curve } \\
\hline$\uparrow$ & \multicolumn{4}{|c|}{$\begin{array}{l}\text { Sign age could not be computed due to curve } \\
\text { trending upwards }\end{array}$} & \multicolumn{2}{|c|}{ Power } & \multicolumn{3}{|c|}{ Power curve } & \\
\hline Lin & \multicolumn{4}{|c|}{ Linear curve } & \multicolumn{2}{|c|}{ Exp } & \multicolumn{3}{|c|}{ Exponential curve } & \\
\hline Log & \multicolumn{4}{|c|}{ Logarithmic curve } & \multicolumn{2}{|c|}{$>80$} & \multicolumn{3}{|c|}{$\begin{array}{l}\text { Very large value } \\
\end{array}$} & \\
\hline
\end{tabular}

Table 3 shows that among Type I yellow signs, the FHWA study linear curve again had a relatively high $R^{2}$ value of 0.39 and reached $20 R_{a}$ at 15 years. Hence this linear curve was chosen for Type I yellow signs. For Type III yellow signs, the FHWA linear curve had the highest $R^{2}$ value of 0.31 , but it also had very high age at which the curve reached $R_{a}=20$. The Purdue polynomial curve had an $\mathrm{R}^{2}$ value of 0.26 . Since the Purdue polynomial that retroreflectivity would hit $20 R_{a}$ at a more reasonable 24 years, this model was selected.

Table 3. $\mathbf{R}^{2}$ Values and Extrapolated Sign Life for Yellow Signs

\begin{tabular}{|c|c|c|c|c|c|c|c|c|c|c|}
\hline \multirow{2}{*}{ Study } & \multicolumn{5}{|c|}{$\mathbf{R}^{2}$ Values } & \multicolumn{5}{|c|}{ Sign Age at $R_{a}=\mathbf{2 0}$} \\
\hline & Lin & Log & Poly & Pow & Exp & Lin & $\log$ & Poly & Pow & $\operatorname{Exp}$ \\
\hline \multicolumn{11}{|c|}{ Type I Signs } \\
\hline FHWA & 0.39 & - & - & - & - & 15 & - & - & - & - \\
\hline NCSU & 0.22 & 0.11 & 0.24 & 0.12 & 0.23 & 21 & $>80$ & 16 & $>80$ & 21 \\
\hline \multicolumn{11}{|c|}{ Type III Signs } \\
\hline FHWA & 0.31 & - & - & - & - & 50 & - & - & - & - \\
\hline OR & 0.08 & 0.09 & 0.09 & 0.05 & 0.05 & 39 & $>80$ & $\uparrow$ & $>80$ & 42 \\
\hline Purdue & 0.17 & 0.07 & 0.26 & 0.07 & 0.17 & 57 & $>80$ & 24 & $>80$ & $>80$ \\
\hline NCSU & 0.06 & 0.07 & 0.09 & 0.07 & 0.08 & $>80$ & $>80$ & 31 & $>80$ & $>80$ \\
\hline
\end{tabular}

Based on Table 4 the following observations emerged for red signs. For Type I red signs the $\mathrm{R}^{2}$ values of the NCSU data curves were near 0.40 for all curve types. This was higher than the $\mathrm{R}^{2}$ 
value of the linear curve from the FHWA study. The research team decided to consider the linear curve $\left(R^{2}=0.37\right.$, sign age at $R_{a}=4$ is 14 years) as the best fit curve in order to maintain consistency in type of model chosen among the different colors of Type I signs. For Type III red signs the polynomial curve plotted from the NCSU study had the highest $\mathrm{R}^{2}$ value (0.48); however, the predicted sign life of 11 years for this curve was not consistent with the results of all other models and sign colors. The exponential curve plotted from the NCSU data also had a large $\mathrm{R}^{2}$ value, but the NCSU research team chose the linear curve because the 21-year sign life is more reasonable. None of the other studies provided superior models.

Table 4. $\mathbf{R}^{2}$ Values and Extrapolated Sign Life for Red Signs

\begin{tabular}{|c|c|c|c|c|c|c|c|c|c|c|}
\hline \multirow{2}{*}{ Study } & \multicolumn{5}{|c|}{$\mathbf{R}^{2}$ Values } & \multicolumn{5}{|c|}{ Sign Age at $R_{a}=4$} \\
\hline & Lin & Log & Poly & Pow & Exp & Lin & Log & Poly & Pow & Exp \\
\hline \multicolumn{11}{|c|}{ Type I Signs } \\
\hline FHWA & 0.21 & - & - & - & - & 14 & - & - & - & - \\
\hline NCSU & 0.37 & 0.36 & 0.37 & 0.31 & 0.40 & 14 & 20 & 15 & 18 & 13 \\
\hline \multicolumn{11}{|c|}{ Type III Signs } \\
\hline FHWA & 0.17 & - & - & - & - & $\uparrow$ & - & - & - & - \\
\hline OR & 0.12 & 0.06 & 0.20 & 0.07 & 0.13 & 39 & $>80$ & 17 & $>80$ & 78 \\
\hline Purdue & 0.34 & 0.34 & 0.36 & 0.24 & 0.28 & 24 & $>80$ & $\uparrow$ & $>80$ & 43 \\
\hline NCSU & 0.35 & 0.15 & 0.48 & 0.20 & 0.42 & 21 & $>80$ & 11 & $>80$ & 43 \\
\hline
\end{tabular}

For Table 5 the selection of curves for Type I and III green signs was straightforward. Only the FHWA linear curves had relatively high $\mathrm{R}^{2}$ values and predicted reasonable times (19 and 37 years) at which signs would reach $R_{a}=4$. Although the Type I NCSU polynomial curve had a larger $\mathrm{R}^{2}$ than the FHWA linear curve, it was not selected because the curve trended upwards.

Table 5. $\mathbf{R}^{2}$ Values and Extrapolated Sign Life for Green Signs

\begin{tabular}{|c|c|c|c|c|c|c|c|c|c|c|}
\hline \multirow{2}{*}{ Study } & \multicolumn{5}{|c|}{$\mathbf{R}^{2}$ Values } & \multicolumn{5}{|c|}{ Sign Age at $R_{a}=4$} \\
\hline & Lin & Log & Poly & Pow & Exp & Lin & Log & Poly & Pow & Exp \\
\hline \multicolumn{11}{|c|}{ Type I Signs } \\
\hline FHWA & 0.31 & - & - & - & - & 19 & - & - & - & - \\
\hline NCSU & 0.27 & 0.27 & 0.36 & 0.19 & 0.18 & 21 & 41 & $\uparrow$ & 33 & 19 \\
\hline \multicolumn{11}{|c|}{ Type III Signs } \\
\hline FHWA & 0.48 & - & - & - & - & 37 & - & - & - & - \\
\hline OR & 0.00 & 0.01 & 0.09 & 0.01 & 0.00 & $\uparrow$ & $\uparrow$ & 13 & $\uparrow$ & $\uparrow$ \\
\hline Purdue & - & - & - & - & - & - & - & - & - & - \\
\hline NCSU & 0.06 & 0.02 & 0.11 & 0.02 & 0.06 & $\uparrow$ & $\uparrow$ & 34 & $\uparrow$ & $\uparrow$ \\
\hline
\end{tabular}




\section{DETERIORATION MODEL INCORPORATING SIGN LOCATION}

Looking at the selected model results from Tables 2 through 5, the authors felt that although some of the $\mathrm{R}^{2}$ values were respectable (given the general scattered nature of the retroreflectivity data shown in Figure 5), the sign age estimates tended to be significantly longer than seen in practice. As a result the authors sought a way to improve the deterioration models, especially in the areas of sign lifetime prediction, and to look for other factors that would explain the scatter.

\section{Survival Analysis}

Initially the authors considered the area of survival or duration analysis, which models (for some population) the distribution of time between two events. In our case the events are when a sign is first put into service and when its retroreflectivity falls below an established minimum. Survival analysis can also estimate the effect of various factors on the overall survival (life) time. Survival analysis data for a population is generally collected at regular time intervals, such as annually. Looking at the sign data from the literature as well as from the NCSU study, the authors found that all of the sign data was what is called "current status data." In other words it is actually population data that was collected once rather than at several intervals over time. This results in the data being heavily left and right censored, with only a very small percentage of the signs being at failure/death (the established $\mathrm{R}_{\mathrm{a}}$ minimum) when the data was collected. Because the sign deterioration data contains only one $\mathrm{R}_{\mathrm{a}}$ measurement of each sign, greater statistical certainty about sign lifetime can be gathered from a regression analysis than from a survival analysis. In other words there simply isn't enough long term data on older signs to establish the second event.

\section{Analysis Modifications}

The authors also revisited the hypothesis that location may have an effect on sign deterioration, although other sign studies have found location not to be as significant as sign age. In the area of pavement deterioration, significant regional effects have been identified (Al-Suleiman 1991). The authors felt that location differences could provide an explanation for some of the data variation and that location might account for both environmental differences and sign management differences. To test this hypothesis the NCSU data was divided by the five NCDOT divisions they were collected in before the new regression models were run. The five NCDOT division locations are shown in Figure 7. They range from coastal areas (Divisions 2 and 6) to mountainous areas (Divisions 12 and 13). For some sign sheeting type and color combinations, some divisions' data were excluded from the regression models because of insufficient or poorly distributed data. 


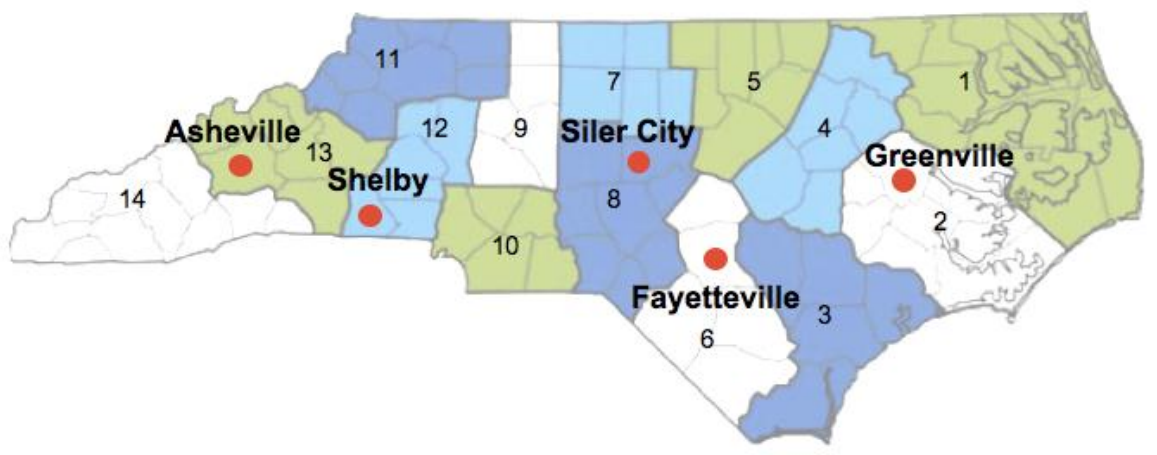

Figure 7. NCSU/NCDOT Sign Data Collection Locations

\section{Significance of Sign Location}

For the $\mathrm{R}_{\mathrm{a}}$ vs. sign age relationship, new linear regression models were calculated from the NCSU data for each sheeting type and color combination that determined a different slope and intercept for each NCDOT division with sufficient data for that sign sheeting type and color combination. In all eight of these "division-separated" regression models, the F-values for the division-based intercepts were large enough to indicate that the null hypothesis should be rejected, signifying that division (location) is a significant factor influencing retroreflectivity deterioration.

Table 6 gives the sign age estimates at $R_{a}=50$, the FHWA minimum, from the new divisionseparated linear regression model for Type I white signs. The estimates, shown in the third column, are for each NCDOT division, and an average over all divisions was also calculated. Looking at the number of observations used to determine each model (column 2), the divisions with more observations (e.g. 6, 12, and 13) have narrower 95\% confidence limits for the age estimate than the divisions with fewer observations. Division 8 has a much higher age estimate than the other divisions, but only had 11 observations, making division 8's age estimate less certain. For the divisions more observations, it seems reasonable to predict that a Type I white sign would reach a $R_{a}$ of 50 between 6 and 8 years old for divisions 2 and 12, and between 9 and 11 years for division 13. This difference in estimated lifetime could be due to variations in sun exposure. Division 13 is situated in a mountainous area where many signs are shaded, while divisions 6 and 12 are in fairly open and exposed rural/suburban settings.

Table 6: Age Estimate at FHWA Minimum for Type 1 White by NCDOT Division

\begin{tabular}{||c||c|c|c|c||}
\hline \hline $\begin{array}{c}\text { NCDOT } \\
\text { Division }\end{array}$ & $\begin{array}{c}\text { Number of Type I } \\
\text { White Signs Measured }\end{array}$ & $\begin{array}{c}\text { Age Estimate @ } \\
\mathbf{R}_{\mathbf{a}}=\mathbf{5 0}\end{array}$ & \multicolumn{2}{|c|}{$\begin{array}{c}\mathbf{9 5 \%} \text { Confidence } \\
\text { Limits }\end{array}$} \\
\hline \hline 2 & 16 & 8.6 & 6.4 & 10.8 \\
\hline 6 & 79 & 7.3 & 6.2 & 8.4 \\
\hline 8 & 11 & 13.4 & 10.8 & 15.9 \\
\hline 12 & 60 & 7.1 & 6.0 & 8.3 \\
\hline 13 & 109 & 10.4 & 9.4 & 11.4 \\
\hline \hline All Divisions & $\mathbf{2 7 5}$ & $\mathbf{9 . 3}$ & $\mathbf{8 . 6}$ & $\mathbf{1 0 . 1}$ \\
\hline
\end{tabular}




\section{Average Sign Lifetime Estimates for the Division-Separated Regression Models}

Division-separated linear regression models were generated for all eight sign sheeting type and color combinations. Table 7 presents the average sign lifetime estimates with $95 \%$ confidence intervals for both the NCDOT and FHWA minimum retroreflectivity levels. A risk level of 5\% is considered acceptable for retroreflectivity deterioration (Lundkvist 2007). The sign lifetime estimates presented in the fifth and seventh columns of Table 7 are an average of all of the NCSU study data over all NCDOT divisions. Some sign color/sheeting combinations do not average sign lifetime estimates from all five NCDOT division because of insufficient data in certain divisions. The $95 \%$ confidence intervals are wider for Type III signs due to smaller sample size and a lack of data on older signs. White signs have two different FHWA minimums; a minimum of $R_{a}=35$ for stop sign legend applications and a minimum of $R_{a}=50$ for black on white background applications.

Table 7: Average Lifetime Estimates for the Division-Separated NCSU Regression Models

\begin{tabular}{||c|c||c|c||c|c||c|c||}
\hline Color & \multirow{2}{*}{$\begin{array}{c}\text { Sign Type } \\
\text { (beaded) }\end{array}$} & $\mathbf{n}$ & $\mathbf{R}^{2}$ & $\begin{array}{c}\text { Age at } \\
\text { NCDOT } \\
\text { minimum } \\
\text { (years) }\end{array}$ & $\begin{array}{c}\text { 95\% } \\
\text { Confidence } \\
\text { Interval }\end{array}$ & $\begin{array}{c}\text { Age at } \\
\text { FHWA } \\
\text { minimum } \\
\text { (years) }\end{array}$ & $\begin{array}{c}95 \% \\
\text { Confidence } \\
\text { Interval }\end{array}$ \\
\hline \hline White & I & 275 & $0.31^{*}$ & 13 & $(11,14)$ & $11\left(\mathrm{R}_{\mathrm{a}}=35\right)$ & $(10,12)$ \\
\cline { 6 - 8 } & & & & $9.3\left(\mathrm{R}_{\mathrm{a}}=50\right)$ & $(8.6,10.1)$ \\
\hline White & III & 54 & $0.31^{*}$ & 16 & $(7,25)$ & $15\left(\mathrm{R}_{\mathrm{a}}=35\right)$ & $(7,24)$ \\
\hline Yellow & I & 259 & $0.24^{*}$ & 10 & $(8,11)$ & $14\left(\mathrm{R}_{\mathrm{a}}=50\right)$ & $(7,22)$ \\
\hline Yellow & III & 34 & 0.14 & 14 & $(5,22)$ & 12 & $(6.1,7.1)$ \\
\hline Red & I & 42 & $0.58^{*}$ & 10 & $(8,11)$ & 8 & $(7,19)$ \\
\hline Red & III & 43 & $0.47^{*}$ & 11 & $(8,13)$ & 10 & $(8,12)$ \\
\hline Green & I & 27 & $0.43^{*}$ & 11 & $(9,14)$ & 9 & $(7,11)$ \\
\hline Green & III & 13 & 0.04 & 17 & $(3,30)$ & 14 & $(7,21)$ \\
\hline
\end{tabular}

*Regression model $p$ values are less than 0.005

${ }^{a}$ Sheeting type not recommended for use by FHWA

For comparison and evaluation purposes, the number of observations (n) and the $\mathrm{R}^{2}$ values for each model are given. Six out of the eight regression models had $\mathrm{p}$ values less than 0.005, indicating that the model coefficients and overall model are significant. The yellow and green Type III models had larger p-values, indicating that these two models need some improvement. For the yellow and green Type III models, only one division had sufficient data. The shaded rows in Table 7 indicate the four models (white Type III, red Type I and III, and green Type I) that have higher $\mathrm{R}^{2}$ values than the corresponding "best" literature models identified in Tables 25 .

\section{SUMMARY AND CONCLUSIONS}

As a result of the FHWA minimum retroreflectivity standards, many US highway agencies are trying to better manage their sign assets. As part of this effort, the NCDOT commissioned 
NCSU to develop a simulation of the sign inspection process. An essential part of the simulation is prediction of the rate at which sign retroreflectivity decreases with sign age. The purpose of the study was to identify or determine the best sign deterioration prediction curves for Type I and III white, yellow, red, and green signs. This paper reports on the results of that effort.

To determine the final deterioration curves, the NCSU research team conducted a comprehensive study of available previously published research papers and reports related to sign retroreflectivity deterioration. Earlier study data was re-analyzed to try to discover the optimal function form (for each sign color and type) to predict sign deterioration rates. The NCSU research team also gathered its own sample of retroreflectivity measurements from over 1000 signs across North Carolina.

Table 8 summarizes the findings from this work. Six of the selected deterioration models resulted from the FHWA study and two were from the Purdue study. The curve selected from the Purdue study for Type III yellow was polynomial, while all of the others were linear. The selected curve for Type III white signs had the lowest $\mathrm{R}^{2}$ value of only 0.19 and an implausible prediction that signs would not drop to a level of $20 \mathrm{R}_{\mathrm{a}}$ until they were 59 years old. The other seven curves were better, with $\mathrm{R}^{2}$ values ranging from 0.21 to 0.52 and predictions that signs would reach the NCDOT visual $R_{a}$ minimum between 14 and 37 years. The p-values for the regression coefficients and for the overall regression models are significant. However, the standard errors in Table 8 are not as low as the research team would like. The variance in all of the studies is probably due to a combination of dissimilarities in the study, measurement method error, retroreflectometer error, and uncontrolled conditions in the field. Hence, Table 8 gives a set of the best available sign deterioration curves that those interested in modeling sign performance can use with some confidence, but there is certainly room for future improvement in prediction and precision.

Table 8. Literature Data Summary

\begin{tabular}{|c|c|c|c|c|c|c|c|}
\hline $\begin{array}{l}\text { Sign } \\
\text { Color }\end{array}$ & $\begin{array}{l}\text { Sign } \\
\text { Type }\end{array}$ & $\begin{array}{l}\text { Data } \\
\text { Source }\end{array}$ & $\begin{array}{c}\text { Equation } \\
\mathbf{y}: \mathbf{R}_{\mathrm{a}} \\
\mathrm{x}: \text { sign age }[\operatorname{year}(\mathrm{s})]\end{array}$ & $\mathbf{R}^{2}$ & $\begin{array}{c}\text { Regression } \\
\text { Standard } \\
\text { Error }\end{array}$ & $\begin{array}{c}\text { Age at } \\
\text { NCDOT } \\
\text { minimum } \\
\text { (years) }\end{array}$ & $\begin{array}{c}\text { Age at } \\
\text { FHWA } \\
\text { minimum } \\
\text { (years) }\end{array}$ \\
\hline \multirow{4}{*}{ White } & \multirow{2}{*}{ I } & \multirow{2}{*}{ FHWA } & \multirow{2}{*}{$y=103.085-5.451 x$} & \multirow{2}{*}{.52} & \multirow{2}{*}{19.1} & \multirow{2}{*}{15} & $13\left(\mathrm{R}_{\mathrm{a}}=35\right)$ \\
\hline & & & & & & & $10\left(\mathrm{R}_{\mathrm{a}}=50\right)$ \\
\hline & \multirow{2}{*}{ III } & \multirow{2}{*}{ FHWA } & \multirow{2}{*}{$y=304.089-4.815 x$} & \multirow{2}{*}{.19} & \multirow{2}{*}{32.7} & \multirow{2}{*}{59} & $56\left(\mathrm{R}_{\mathrm{a}}=35\right)$ \\
\hline & & & & & & & $53\left(\mathrm{R}_{\mathrm{a}}=50\right)$ \\
\hline \multirow[b]{2}{*}{ Yellow } & $\mathrm{I}$ & FHWA & $y=78.794-3.906 x$ & .39 & 17.0 & 15 & $7^{\mathrm{a}}$ \\
\hline & III & Purdue & $\begin{array}{l}y=-0.552 x^{2}+5.644 x+ \\
193.01\end{array}$ & .26 & 33.6 & 24 & 22 \\
\hline \multirow{2}{*}{ Red } & I & NCSU & $y=13.085-0.635 x$ & .37 & 3.0 & 14 & 10 \\
\hline & III & NCSU & $y=59.632-2.658 x$ & .35 & 9.7 & 24 & 20 \\
\hline \multirow{2}{*}{ Green } & I & FHWA & $y=15.990-0.637 x$ & .31 & 3.4 & 19 & 14 \\
\hline & III & FHWA & $\mathrm{y}=53.386-1.345 \mathrm{x}$ & .48 & 7.7 & 37 & 35 \\
\hline
\end{tabular}

${ }^{a}$ Sheeting type not recommended for use by FHWA

Type III signs have much higher retroreflectivity values than Type I signs for the samples examined in this paper, which are almost all less than 15 years old. This allows a couple of 
observations to be made. First, if highway agencies replace their Type I signs with Type III signs, retroreflectivity values will significantly increase and essentially remove retroreflectivity as a concern for many years while simultaneously lowering life-cycle costs (Rys and Russell 1995). Second, there is a weak basis for predicting how signs will perform after 15 years or so in the field. For this study the research team assumed that Type III signs will last as long or longer than Type I signs, but there is no empirical evidence to support that assumption at this point. Quite simply, these signs have not been in place long enough to provide adequate data to work with.

The research found that $\mathrm{R}^{2}$ values were usually less than ideal for the trend lines between age and retroreflectivity. Almost all of the $\mathrm{R}^{2}$ values from the NCSU data or from the literature were less than 0.5 , and many were less than 0.1 . This likely means that may be other factors besides age influence the rate at which signs deteriorate. These factors include measurement method error, retroreflectometer error, and uncontrolled field conditions which lead to damage and weathering. Although the effect of each individual factor may be low, as the literature suggests, the factors collectively cause the scatter in the data. When the authors re-analyzed the NCSU data including NCDOT division as a factor that could account for some location and management differences, significant performance variations from division to division were found. The division-separated linear regression model for Type III white signs is a good alternative to the selected literature Type III white sign model (FHWA model).

In this paper the discussion was confined to age, which we considered to be the most important factor causing deterioration, and sign location. The other factors, if considered, would be helpful in designing a microscopic simulation of sign performance but would make the simulation results almost impossible to apply for most highway agencies. The NCDOT, for example, relies on qualitative visual nighttime sign inspections and does not maintain a sign inventory, so at this point a sign management system that requires any information besides sign color, type, approximate location, and age, cannot be practically used.

\section{FUTURE RESEARCH}

There are several prime avenues for productive future research to follow up this work. First, future researchers should collect more Type III sign data as the data that were collected in this study and that reported by numerous other studies was primarily for Type I signs. The weakest selected model, i.e., the least amount of reliable available data, was for Type III white signs. Additional studies should also collect more data on old Type III signs (older than 15 years) in order to derive a more accurate deterioration curve for the latter stages of sign life.

Second, a key limitation of all existing studies is the wide data scatter and short duration of data collection. Essentially only snapshots in time are available rather than systematic multi-year studies. As a result, AASHTO should consider conducting research for more than 3 years in its NTPEP program to provide researchers with a more comprehensive data set. If signs were left in place longer more well-founded deterioration rates would be available for study and analysis that would benefit the Departments of Transportation across the country, especially as they attempt to develop strategies to meet the new minimum retroreflectivity standard. The availability of longer term data would also provide researchers with the opportunity to explore other modeling approaches such as survival analysis. 
If AASHTO is unwilling or unable to extend its program test duration, states should consider establishing their own sign testing facilities. This will help the individual states in having data for their respective geographic locations and climatic conditions. The authors have designed an experimental sign facility intended to meet a wide variety of long term retroreflectivity data needs as well as provide other sign performance data (Rasdorf et al. 2008). The facility includes a base facility design and suggested optional modifications to show how the design can be customized or expanded, depending on an agency's unique needs. Seventeen years ago, FHWA researchers recommended that "a controlled study where climate is constant should be undertaken at approximately 10 sites across the country" (Black et al. 1991).

Third, future studies should be conducted under natural field conditions, i.e., without cleaning signs. Cleaning will give a higher retroreflectivity but it does not represent signs that drivers see at night. Drivers see signs in their natural state and hence, cleaning a sign will not give the desired solution.

Finally, future research must consider not only age, but also other factors that affect sign deterioration. This will help feed a more accurate microscopic simulation. Efforts could then be made to insure that the simulation results could be practically applied even in that do not currently maintain a sign inventory.

\section{ACKNOWLEDGEMENTS}

This work was sponsored by the NCDOT. The views expressed in this paper are those of the authors and do not necessarily reflect the views of the NCDOT or any other organization. The authors alone are responsible for any errors. This paper does not represent a standard, guideline, or specification of the NCDOT, FHWA, or any other organization. The authors wish to thank Muhtar Osman and the NCSU statistical consulting program for assistance. 


\section{REFERENCES}

Al-Suleiman, T. I., Sinha, K. C., and Riverson, J.D. (1991). "Effects of pavement age and traffic on maintenance effectiveness." Journal of Transportation Engineering, 117(6), 644-659.

American Association of State Highway and Transportation Officials (AASHTO), (2006). "National Transportation Product Evaluation Program, Sign Sheeting Materials." Submittal Year 2002, SSM number 0910, North Carolina DOT and Arizona DOT, Flagstaff. <http://data.ntpep.org/ssm/ssm.asp.> (Oct. 4, 2006.)

AASHTO, (2005a). "National Transportation Product Evaluation Program". <http://www.ntpep.org> (Dec. 15, 2005).

AASHTO, (2005b). "Three year results of outdoor exposure data on sign sheeting materials." 2000 NTPEP Deck, AASHTO's National Transportation Product Evaluation Program.

AASHTO, (2000). "Minimum levels of retroreflectivity for signs." Retroreflectivity Policy Resolution.

Bischoff, A. and Bullock, D. (2002). "Sign retroreflectivity study." Final Report, Indiana Department of Transportation, West Lafayette, IN.

Black, K. L., McGee, H. W., Hussain, S. F., and Rennilson, J. J. (1991). "Service life of retroreflective signs." FHWA-RD-90-101, Federal Highway Administration, Washington, DC.

Carlson, P. J. and Hawkins, H. J. (2003). "Updated minimum retroreflectivity levels for traffic signs." FHWA-RD-03-081, USDOT, FHWA Office of Safety, Washington, DC.

Federal Highway Administration (FHWA), (2007). "Manual on uniform traffic control devices for streets and highways, 2003 edition with revisions 1 and 2 incorporated." $U . S$. Department of Transportation, Washington, D.C.

Kirk, A. R., Hunt, E. A., and Brooks, E. W. (2001). "Factors affecting sign retroreflectivity." Final Report OR-RD-01-09, Oregon Department of Transportation, Salem, OR.

Kirtley, N. and Rasdorf, W. (2001). "Sign count approximation using field inventory sampling and calculated sign densities for NC primary routes." Technical Report, Department of Civil Engineering, NC State University. Raleigh, NC.

Lundkvist, S. and Isacsson, U. (2007). "Prediction of road marking performance." Journal of Transportation Engineering, 133(6), 341-346.

McGee, W. H. and Paniati, J. A. (1998). "An implementation guide for minimum retroreflectivity requirements for traffic signs." FHWA-RD-97-052, Federal Highway Administration, Washington, D.C. 
McGee, W. H. and Taori, S. (1998). "Impacts on state and local agencies for maintaining traffic signs within minimum retroreflectivity guidelines." FHWA-RD-97-053, Federal Highway Administration, Washington, D.C.

Palmquist, M. and Rasdorf, W. (2002). "Sign count approximation using field inventory sampling and calculated sign densities: analysis improvements, and methods." Technical Report, Department of Civil Engineering, NC State University, Raleigh, NC.

Rasdorf, W., Harris, E. A., and Hummer, J. E. (2008). "Designing an experimental facility for roadway sign retroreflectivity measurement." IMSA Journal, Jan./Feb. 2008, 44-55.

Rasdorf, W., Hummer, J. E., Harris, E. A., Immaneni, V. P., and Yeom, C. (2006). "Designing an efficient nighttime sign inspection program that ensures motorist safety." Technical Report No. FHWA/NC/2006-08, North Carolina Department of Transportation, Raleigh, $\mathrm{NC}$.

Rys, M. and Russell, E. R. Sr. (1995). "Methodology to review cost-effective highway sign retroreflective sheeting policy." Journal of Transportation Engineering, 121(2), 176-181.

Wolshon, B., Degeyter, R., and Swargam, J. (2002). "Analysis and predictive modeling of road sign retroreflectivity performance." $16^{\text {th }}$ Biennial Symposium on Visibility and Simulation, Transportation Research Board, Iowa City, IA. 